\title{
Avaliação de óleos, carvão vegetal e vitamina E no desempenho e nas concentrações lipídicas do sangue e dos ovos de poedeiras ${ }^{1}$
}

\section{Flavia Escapini Fanchiotti $2^{2 *}$, George Henrique Kling de Moraes ${ }^{2}$, Anderson de Almeida Barbosa ${ }^{2}$, Luiz Fernando Teixeira Albino ${ }^{3}$, Paulo Roberto Cecon $^{4}$, Adolpho Marlon Antoniol de Moura ${ }^{5}$}

\author{
1 Projeto financiado pela FAPEMIG e CAPES. \\ 2 Departamento de Bioquímica e Biologia Molecular da UFV, 36571-000, Viçosa, MG. \\ 3 Departamento de Zootecnia da UFV, 36571-000, Viçosa, MG. \\ ${ }^{4}$ Departamento de Informática da UFV, 36571-000, Viçosa, MG \\ 5 Departamento de Zootecnia da UENF, 28013-600, Campos dos Goytacazes, RJ.
}

RESUMO - Foram estudados os efeitos de duas fontes de óleo vegetal, de carvão e de vitamina E sobre o desempenho e os níveis lipídicos do sangue e dos ovos de poedeiras comerciais. Utilizaram-se poedeiras Lohmann Brown e Lohmann LSL com 58 semanas de idade. O experimento teve duração de 84 dias, divididos em três períodos de 28 dias, e foi realizado em delineamento inteiramente casualizado em esquema de parcelas subdivididas, tendo nas parcelas um esquema fatorial $8 \times 2$, com oito dietas e duas marcas comerciais, e nas subparcelas os períodos. Para avaliação das características produtivas, colesterol total, triglicérides e HDL sanguíneos, utilizaram-se quatro repetições de seis aves por unidade experimental e, para determinação do colesterol total das gemas, duas repetições. As dietas foram acrescidas de $2,0 \%$ de óleo de soja ou de linhaça em combinação ou não com vitamina E (60 mg/kg de ração) e/ou carvão (2,0\%). Os resultados não evidenciaram diferenças entre as dietas experimentais sobre as variáveis de desempenho. Consumo de ração, espessura da casca, colesterol total e triglicerídios no sangue foram influenciados pelas marcas comerciais e peso médio dos ovos, espessura da casca, colesterol total e triglicerídios no sangue, pelos períodos experimentais. O uso de óleos vegetais, carvão e vitamina E nas dietas experimentais não influencia as características de desempenho nem o perfil lipídico do sangue e de colesterol total da gema dos ovos. Aves Lohmann LSL apresentam maiores consumos de ração e níveis mais altos de colesterol e triglicérides no sangue.

Palavras-chave: características produtivas, gema, lipídios sanguíneos

\section{Evaluation of oil, vegetal charcoal and E vitamin on performance and on blood and egg lipid concentrations of laying hens}

\begin{abstract}
This experiment was carried out to evaluate the effects of two vegetal oils sources, charcoal and vitamin $\mathrm{E}$ on performance and lipid levels in blood and eggs of commercial laying hens. It was used Lohman Brown and Lohman LSL laying hens at 58 weeks of age. The experiment lasted 84 days split in three 28-day periods and it was carried out in a complete random design in a split-plot scheme, in a $8 \times 2$ factorial scheme in the plots with eight diets an two commercial brands, and the periods in the subplots. For evaluation of productive characteristics, total cholesterol, blood tryclecydes and HDL, it was used four repetitions of six birds per experimental unit and, for determination of total yolk cholesterol, two repetitions were used. Diets were added with $2 \%$ soybean oil or linseed oil combined or not with E vitamin (60 mg/kg ration) and/or charcoa (2\%). No diet effects on the performance variables were observed. Commercial strain effects on feed intake, shell thickness, total cholesterol and blood triglycerides and experimental period effects on egg weight, shells thickness, total cholesterol and blood triglycerides were observed. Use of vegetal oil, charcoal and vitamin E in experimental diets do not affect characteristics of performance neither blood lipid and egg yolk total cholesterol profiles. Lohmann LSL birds show higher feed intake and higher levels of cholesterol and triglycerides in the blood.
\end{abstract}

Key Words: blood lipids, production characteristics, yolk

\section{Introdução}

As sugestões de melhoria da saúde humana pela redução do consumo de gordura animal incluem a preocupação com o consumo de ovo, devido à sua elevada concentração de gordura (Tullet, 1987). O ovo é um dos alimentos que contém proteínas de origem animal, de alta qualidade e baixo custo (Goméz, 2003; Braga et al., 2005). Entretanto, tem alto

Recebido em 24/10/2008 e aprovado em 2/12/2009.

Correspondências devem ser enviadas para: ffanchiotti@hotmail.com

* Endereço atual: Núcleo de Nutrição da UFPE/CAV, 55608-680, Vitória de Santo Antão, PE. 
nível de colesterol, motivo pelo qual é desaconselhado seu consumo frequente, principalmente por pessoas com problemas cardiovasculares (Turatti, 2001; Garcia \& Albala, 1998; Oba et al., 2005).

Alguns autores reportaram os efeitos da manipulação dos ingredientes da ração de poedeiras sobre os níveis de colesterol da gema. Em muitos casos, os resultados obtidos não são aqueles esperados, havendo muitas controvérsias, pois dependem da absorção, síntese, distribuição e excreção do colesterol entre o intestino das aves e o ovo (Noble et al., 1990).

Souza et al. (1998) trabalharam com dietas contendo cinza de carvão vegetal e descreveram reduções significativas nos teores de colesterol do sangue, da carne e do ovo de poedeiras, além de melhoria da produtividade das aves e maior resistência da casca dos ovos. No entanto, o mecanismo pelo qual a redução dos teores de colesterol foi obtida permanece desconhecido.

Sim \& Bragg (1977), Holland et al. (1980), Hargis et al. (1991) e Mori et al.(1999) descreveram que a inclusão de óleos vegetais ricos em ácidos graxos poliinsaturados na ração de poedeiras pode reduzir a concentração de colesterol na gema e no plasma. No entanto, os resultados encontrados na literatura são contraditórios (Costa et al., 2008).

Os óleos contendo ácidos graxos poliinsaturados são particularmente propensos ao ataque de radicais livres e à deterioração oxidativa (Wanasundara \& Shahidi, 1998). Jiang et al. (1992) reportaram alta incidência de sabor e odor de peixe nos ovos de poedeiras alimentadas com rações contendo linhaça. Esse sabor e odor desagradável foi atribuído à oxidação do óleo de linhaça. A adição de vitamina $\mathrm{E}$ ou outros antioxidantes nas rações ricas em poliinsaturados pode prevenir essa oxidação.

Considerando esses aspectos, este trabalho foi realizado com os objetivos de estudar os efeitos da inclusão de duas fontes de óleo vegetal (óleo de soja e óleo de linhaça), de resíduo de carvão e de vitamina E em rações para poedeiras comerciais sobre os níveis lipídicos do sangue e colesterol total dos ovos, e testar a influência dessas substâncias no desempenho das aves.

\section{Material e Métodos}

Foram utilizadas 384 poedeiras comerciais, sendo 192 semipesadas Lohmann Brown e 192 leves Lohmann LSL com 58 semanas de idade no início do experimento. O manejo adotado foi o tradicionalmente utilizado em granjas comerciais de postura, com alimento e água à vontade durante todo o período experimental, seguindo as recomendações contidas nos manuais das marcas comerciais. A coleta dos ovos foi realizada duas vezes ao dia, no período da manhã e à tarde e o programa de luz adotado foi de 17 horas diárias.

As aves foram alojadas em gaiolas de arame galvanizado com subdivisões de $25 \times 40 \times 40 \mathrm{~cm}$, contendo duas aves por subdivisão, dispostas horizontalmente e sobrepostas em duas fileiras de cada lado. Os bebedouros utilizados foram do tipo calha e os comedouros, do tipo linear de madeira. As rações experimentais (Tabela 1) foram preparadas conforme recomendações preconizadas por Rostagno et al. (2000) a fim de atender às necessidades nutricionais das aves.

Utilizou-se um esquema de parcela subdividida, tendo na parcela um esquema fatorial $8 \times 2$, com oito dietas e duas marcas comerciais, e na subparcela os períodos (28, 56 e 84 dias), em um delineamento experimental inteiramente casualizado com quatro repetições de seis aves por unidade experimental para as características produtivas e os teores de colesterol total, triglicérides e HDL no sangue. Para o colesterol total das gemas, foram utilizadas duas repetições com seis aves.

As dietas experimentais foram à base de milho e farelo de soja e acrescidas de óleo de soja (2,0\%) e/ou óleo de linhaça (2,0\%) em combinação ou não com vitamina $\mathrm{E}$ (60 mg/kg de ração) ou carvão vegetal (2,0\%), totalizando oito dietas

Tabela 1 - Composição das rações experimentais

\begin{tabular}{|c|c|}
\hline Ingrediente & $\%$ \\
\hline Milho & 60,87 \\
\hline Farelo de soja & 23,47 \\
\hline Calcário & 8,800 \\
\hline Fosfato bicálcico & 1,502 \\
\hline L-lisina.HCl & 0,032 \\
\hline DL-metionina & 0,156 \\
\hline Sal comum & 0,480 \\
\hline Suplemento vitamínico ${ }^{1}$ & 0,100 \\
\hline Suplemento mineral ${ }^{2}$ & 0,050 \\
\hline Antioxidante $^{3}$ & 0,020 \\
\hline Cloreto de colina & 0,020 \\
\hline Óleo vegetal ${ }^{4}$ & 2,000 \\
\hline Porção variável ${ }^{5}$ & 2,500 \\
\hline \multicolumn{2}{|l|}{ Composição nutricional (calculada) } \\
\hline Proteína bruta (\%) & 16,00 \\
\hline Energia metabolizável (kcal/kg) & 2800 \\
\hline Fósforo disponível (\%) & 0,375 \\
\hline Cálcio (\%) & 3,790 \\
\hline Metionina + cistina total (\%) & 0,682 \\
\hline Metionina total (\%) & 0,410 \\
\hline Lisina total (\%) & 0,839 \\
\hline
\end{tabular}

${ }^{1}$ Suplemento vitamínico: Rovimix (Roche). Níveis de garantia por quilo do produto: vit. A - 10.000.000 UI; vit. $\mathrm{D}_{3}-2.000 .000 \mathrm{UI}$; vit. E - $30.000 \mathrm{UI}$; vit. $\mathrm{B}_{1}-2,0 \mathrm{~g}$; vit. $\mathrm{B}_{6}-4,0 \mathrm{~g}$; ácido pantotênico - 12,0 g; biotina - 0,10 g; vit. $\mathrm{K}_{3}$ - 3,0 g; ácido fólico - 1,0 g; ácido nicotínico - 50,0 g; vit. $\mathrm{B}_{12}-15.000 \mathrm{mcg}$; Se - 0,25 g; veículo q.s.p. - 1.000 g.

2 Suplemento mineral: Roligomix (Roche). Níveis de garantia por quilo do produto: Mn - 16,0 g; Fe - 100,0 g; Zn -100,0 g; Cu - 20,0 g; Co - 2,0 g; I - 2,0 g e Veículo q.s.p. - $1.000 \mathrm{~g}$.

${ }^{3}$ Hidroxi-butil-tolueno (BHT).

4 Óleo vegetal: óleo de soja (dietas 1, 2, 3 e 4); óleo de linhaça (dietas 5, 6, 7 e 8).

5 Porção variável: $60 \mathrm{mg}$ de vit. E/kg (dietas 2 e 6), $20 \mathrm{~g}$ de carvão vegetal $/ \mathrm{kg}$ (dietas 3 e 7), 60 mg de vit. E/kg + 20 g de carvão vegetal $/ \mathrm{kg}$ (dietas 4 e 8), completando os 2,5\% com areia lavada. 
experimentais. Ao final de cada período experimental, foram calculados o consumo de ração, em g/ave/dia, a produção de ovos em porcentagem, calculada dividindo-se o total de ovos produzidos pelo número de aves de cada parcela (Judice et al., 2002; Silva, 2000) e a conversão alimentar, obtida dividindo-se o total de ração consumida pelo peso dos ovos produzidos e expressa em gramas de ração por grama de ovo produzido. Com o peso total e o número de ovos por parcela, foi calculada a média das parcelas para a obtenção do peso médio dos ovos/período.

Nos últimos três dias de cada período experimental, três ovos de cada parcela foram selecionados ao acaso. As cascas foram lavadas em água e secas à temperatura ambiente e as medidas de espessura da casca foram tomadas em três pontos da região equatorial do ovo utilizando-se um paquímetro digital (Digimess). Os valores obtidos para os três ovos de cada parcela foram transformados em valores médios por parcela.

As amostras de sangue, de quatro aves por unidade experimental, foram coletadas por punção cardíaca no último dia de cada período experimental, após jejum de 12 horas, para determinação dos níveis de colesterol total, triglicérides e colesterol-HDL. Em cada período experimental, foi utilizada uma ave da parcela, a qual não foi reutilizada para a coleta do próximo período.

Para obtenção do soro, o sangue, depois de coletado, foi deixado em repouso à temperatura ambiente durante 20 minutos e o coágulo obtido foi desprendido cuidadosamente das paredes do tubo por meio de um bastão de vidro de extremidade lisa. Em seguida, as amostras foram centrifugadas a 7100 x g, durante 15 minutos, e, depois da sedimentação do coágulo, o sobrenadante foi pipetado (Lima et al., 2001).

As dosagens de colesterol total e colesterol-HDL foram realizadas pelo método enzimático-colorimétrico, enquanto as dosagens de triglicérides foram pelo método enzimático, utilizando-se kits comerciais da marca Bioclin ${ }^{\circledR}$, e as leituras realizadas no autoanalisador paramétrico para bioquímica (Alizé).

Para determinação do conteúdo de colesterol total nas gemas, foram coletadas três gemas por parcela nos três últimos dias de cada período experimental. As gemas foram liofilizadas para a posterior utilização. A metodologia utilizada foi a descrita por Mazzali et al. (2003).

Antes da quantificação, realizaram-se a saponificação direta das amostras e a extração da matéria insaponificável. Pesou-se 0,25 g de amostra em tubo de ensaio com tampa rosqueável de $70 \mathrm{~mL}$ e adicionaram-se $10 \mathrm{~mL}$ de $\mathrm{KOH} 2 \%$ em etanol absoluto. As amostras foram então colocadas a $50^{\circ} \mathrm{C}$ em banho-maria com agitação por duas horas, adicionadas de $5 \mathrm{~mL}$ de água destilada e deixadas a resfriar.
A matéria insaponificável foi extraída com $10 \mathrm{~mL}$ de hexano agitando-se em vortex por um minuto. A extração foi repetida mais duas vezes e uma alíquota de $3 \mathrm{~mL}$ do extrato de hexano foi seca em nitrogênio e dissolvida em $250 \mathrm{~mL}$ de isopropanol grau cromatográfico. A mistura foi agitada em vortex e, em seguida, foi realizada a reação enzimática utilizando-se o kit colesterol líquido estável (Bioclin ${ }^{\circledR}$ ) com $10 \mathrm{~mL}$ da amostra $1 \mathrm{~mL}$ do reagente de trabalho. As amostras foram colocadas a $37^{\circ} \mathrm{C}$ em banho-maria por 5 minutos.

Em seguida, leu-se a absorvância em espectrofotômetro contra o branco (reagente de trabalho), igualmente preparado, a $500 \mathrm{~nm}$. A curva de calibração foi construída a partir da solução-padrão de colesterol (200 mg/dL), variando de 0,02 a $0,10 \mathrm{mg}$, e os cálculos das diluições foram realizados até se chegar em valores de mg de colesterol/g de gema in natura.

Os dados foram submetidos à análise de variância e de regressão utilizando-se o programa Sistemas de Análises Estatísticas e Genéticas -SAEG (UFV, 2003). Para os fatores qualitativos, as médias foram comparadas utilizando-se os testes de Duncan e/ou F adotando-se o nível de 5\% de probabilidade.

Para o fator quantitativo, os modelos foram escolhidos com base na significância dos coeficientes de regressão utilizando-se o teste t e adotando-se o nível de $5 \%$ de probabilidade no coeficiente de determinação $\left(\mathrm{r}^{2}=\mathrm{S}\right.$. Q. regressão/S. Q. período) e respeitando-se a interpretação biológica para cada variável.

\section{Resultados e Discussão}

Não foi observado efeito significativo das dietas experimentais sobre as variáveis de desempenho. Entretanto, o consumo de ração e a espessura da casca foram influenciados $(\mathrm{P}<0,05)$ pelas marcas comerciais. Também houve efeito dos períodos experimentais sobre o peso médio dos ovos $(\mathrm{P}<0,05)$ e a espessura da casca $(\mathrm{P}<0,01)$ (Tabela 2).

As aves Lohmann LSL consumiram mais ração que as Lohmann Brown, fato explicado pela própria característica da linhagem comercial, uma vez que as poedeiras leves LSL apresentam maior consumo de ração que as da marca Brown (Lohmann Tierzucht, 2009 - inserir nas referências).

O peso médio dos ovos aumentou linearmente em 0,0169 g a cada um dia do período experimental, de acordo com a equação: $\hat{Y}=64,8349+0,0169 x\left(r^{2}=0,99\right)$. Resultados diferentes dos observados neste trabalho foram relatados por Mendonça Jr. et al. (2000) utilizaram óleo de peixe $(2,0 \%)$ na dieta de poedeiras comerciais com 89 semanas de idade e notaram redução no peso dos ovos. Scheideler \& 
Tabela 2 - Desempenho e características dos ovos de poedeiras Lohmann Brown e Lohmann LSL alimentadas com as dietas experimentais

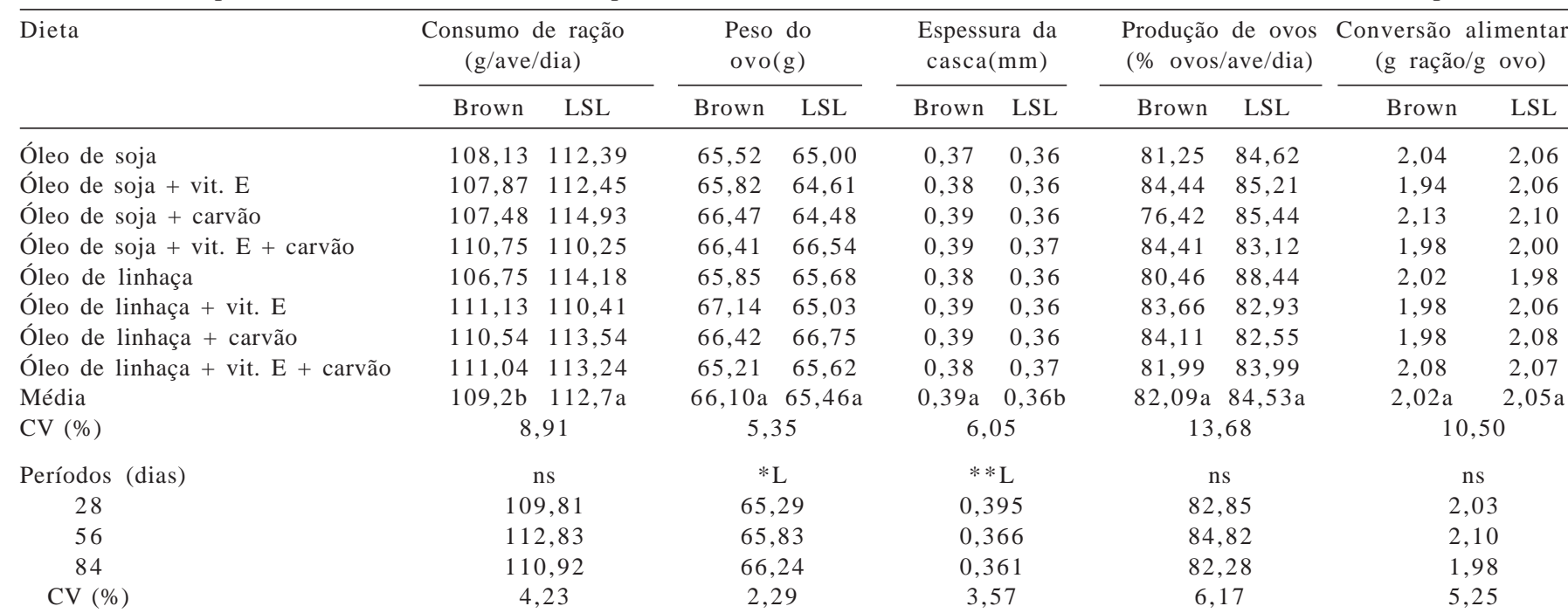

Médias seguidas de letras diferentes na linha para cada variavel diferem entre si a 5\% de probabilidade pelo teste F.

ns: efeito não-significativo dos períodos experimentais $(\mathrm{P}>0,05)$ pela regressão.

**L: efeito para regressão linear $(\mathrm{P}<0,01) \hat{\mathrm{Y}}=0,4069-0,0006 \mathrm{x}\left(\mathrm{r}^{2}=0,90\right)$.

$* \mathrm{~L}$ : efeito para regressão linear $=(\mathrm{P}<0,05) \hat{\mathrm{Y}}=64,8349+0,0169 \times\left(\mathrm{r}^{2}=0,99\right)$.

Froning (1996) também relataram efeitos na redução do peso dos ovos de poedeiras comerciais recebendo diferentes níveis e variedades de linhaça. No entanto, os níveis de linhaça utilizados foram maiores que os utilizados neste trabalho, de 5, 10 e $15 \%$.

De acordo com guia das linhagens comerciais Lohmann, poedeiras semipesadas apresentam maior espessura de casca dos ovos, devido à maior deposição de proteína para formação das membranas internas da casca (Mendonça Jr. et al., 2000).

A espessura de casca reduziu linearmente $(\mathrm{P}<0,01)$ com o aumento do período experimental de acordo com a equação $\hat{Y}=0,4069-0,0006 x\left(r^{2}=0,90\right)$. Houve redução de $0,0006 \mathrm{~mm}$ para cada dia do período experimental, porém isso é observado em aves no final do ciclo de postura ou em segundo ciclo, que apresentam aumento do peso e tamanho do ovo e redução na espessura da casca.

Na análise de variância, não houve efeito significativo das dietas sobre a produção de ovos e a conversão alimentar (Tabela 2). Hargis et al. (1991), utilizando óleo de peixe, que assim como o óleo de linhaça, é rico em ácidos graxos poliinsaturados, também não descreveram efeitos sobre a taxa de postura das aves.

Os efeitos da linhaça sobre a produção de ovos de poedeiras alimentadas por quatro semanas, foram avaliados por Jiang et al. (1991a) que não encontraram efeitos da linhaça sobre a produção de ovos ou sobre o peso dos ovos durante o experimento. No entanto, Scheideler \& Froning (1996) relataram aumento na taxa de postura de poedeiras alimentadas com rações contendo óleo de linhaça.
Contrariamente, Caston et al. (1994) reportaram efeitos negativos do óleo de linhaça, em níveis acima de 20\%, sobre o ganho de peso de poedeiras de 51 e 73 semanas de idade, mas notaram que a produção total de ovos não foi afetada. Da mesma forma, Aymond \& Van Elswyk (1995), em trabalho com aves mais jovens (22 semanas de idade) por um período de cinco semanas, descreveram decréscimos na produção de ovos das poedeiras alimentadas com altos níveis de linhaça (15\%).

Da mesma forma que neste estudo, nenhum efeito sobre a produção de ovos das aves foi constatado por Mazalli et al. (2004), que testaram rações contendo 3\% de diferentes fontes lipídicas, entre elas, óleo de soja, óleo de canola, óleo de girassol, óleo de linhaça e óleo de peixe, associadas a dois níveis de vitamina E (12 e 100 UI/kg de ração).

Resultados contrários aos obtidos neste estudo foram relatados por Oba et al. (2005), que observou que rações contendo cinza vegetal pioraram a conversão alimentar de poedeiras comerciais. Segundo a análise de variância, não houve efeito significativo das dietas sobre o perfil lipídico do sangue nem sobre o colesterol total das gemas dos ovos $(\mathrm{P}>0,05)$. Entretanto, houve efeito das marcas comerciais e dos períodos experimentais sobre as variáveis de colesterol total e triglicerídios no sangue de poedeiras $(\mathrm{P}<0,01)$ (Tabela 3).

Comparando as marcas, observou-se que as aves da marca Lohmann LSL apresentaram concentrações mais elevadas de colesterol total e de triglicerídios no sangue quando comparadas às da marca Lohmann Brown. Isso se deve, possivelmente, ao metabolismo mais acelerado das poedeiras leves em relação às semipesadas, que exigem 
Tabela 3 - Médias do perfil lipídico do sangue e colesterol total da gema dos ovos

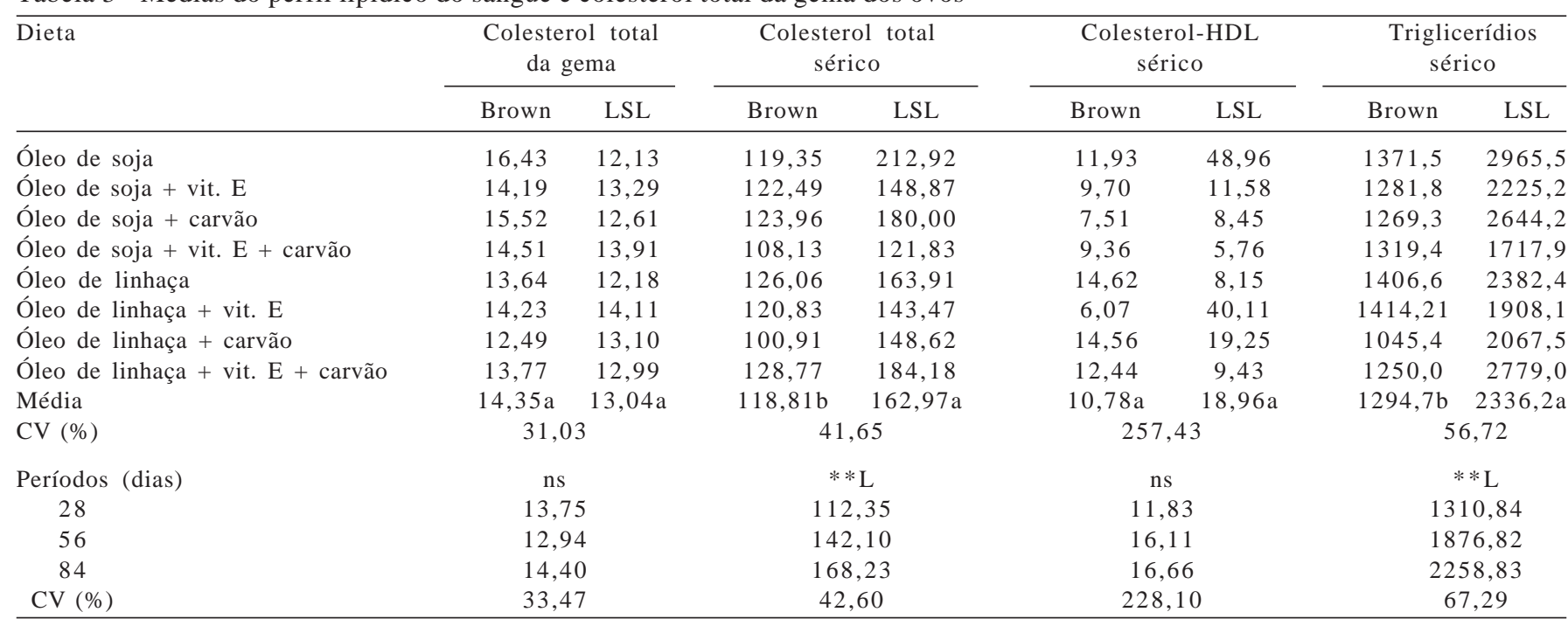

Médias seguidas de letras diferentes na linha para cada variável diferem entre si a 5\% de probabilidade pelo teste F. ns: efeito não-significativo dos períodos experimentais $(\mathrm{P}>0,05)$ pela regressão. $* * \mathrm{~L}$ : efeito para regressão linear $(\mathrm{P}<0,01)$.

maior mobilização de ácidos graxos e hormônios esteroides para síntese de gema que poedeiras pesadas e semipesadas (Klasing, 1998).

$\mathrm{Na}$ análise de regressão, foi verificado efeito linear $(\mathrm{P}<0,01)$ sobre a concentração sérica de colesterol total e triglicerídios. A cada um dia, houve aumento de 0,9978 mg/dL de colesterol no sangue segundo a equação $\hat{Y}=85,0136+0,9978 x\left(r^{2}=0,99\right)$. Para a concentração de triglicerídios, no entanto, ocorreu aumento linear de $16,9285 \mathrm{mg} / \mathrm{dL}$ para cada dia do período experimental nos níveis séricos, de acordo com a equação $\hat{Y}=867,496+16,9285 x\left(r^{2}=0,99\right)$.

De acordo com Souza et al. (1998), a adição de cinza vegetal na ração de poedeiras promoveu reduções nas concentrações de colesterol no sangue e nas gemas dos ovos das aves. Essas reduções foram de 50, 56 e 57\% para colesterol sanguíneo e 17, 21 e 22\% no colesterol da gema quando foram utilizados 1,2 e $3 \%$ de cinza vegetal, respectivamente. Além disso, reduziu a umidade nas fezes das aves, devido à ação adstringente do carvão.

Do mesmo modo que neste estudo, Oba et al. (2005) não observou diferenças significativas nos níveis de colesterol sanguíneo de poedeiras alimentadas com rações contendo $2 \%$ de cinza vegetal.

Kutlu et al. (2001) observaram aumento da excreção de lipídios nas fezes de pintinhos ( 1 a 21 dias) com o aumento dos níveis de carvão na ração, porém não notaram diminuição na gordura corporal e explicaram que a possível causa para isso é a síntese deficiente de bile pelos pintinhos, que dificulta a digestão lipídica, de modo que a gordura proveniente da dieta é adsorvida pelo carvão.
Observando a utilização de diferentes fontes lipídicas sobre a concentração de colesterol sérico, Van Elswyk et al. (1994) notaram que a utilização de óleo de peixe reduziu o colesterol sanguíneo de poedeiras. Fornecendo a poedeiras rações contendo 2 e $4 \%$ de óleo de canola, Mendonça Jr. et al. (1995) não observaram diferenças nos níveis de colesterol e triglicérides no plasma das aves.

Mendonça Jr. et al. (2000) compararam dietas com diferentes níveis de óleo de peixe e não encontraram diferenças significativas nos teores médios de colesterolHDL e triglicérides plasmáticos. Santos (1999), utilizando óleos poliinsaturados marinhos, também observaram que os valores de lipídios sanguíneos mantiveram-se inalterados em relação aos do grupo controle.

De modo geral, ocorreram grandes variações nas dosagens sanguíneas das aves, comprovadas pelos coeficientes de variação. Variações dessa natureza foram descritas por outros autores (Tortuero et al., 1975; Edwards \& Jones, 1964; Oba et al., 2005). De acordo com Jiang et al. (1991b), muitas tentativas têm sido feitas para reduzir o conteúdo de colesterol nos ovos, contudo, praticamente nenhum sucesso tem ocorrido. Os resultados obtidos nesses estudos são controversos e de difícil conclusão prática. Isso porque diferenças metodológicas, ambientais e de modelo experimental influenciam diretamente nos resultados.

Rações ricas em ácidos graxos, como o oleico, linoleico e linolênico, normalmente resultam em aumentos acentuados nas concentrações de lipídios totais da gema, conforme observado por Jiang et al. (1992). Prakash et al. (1996) avaliaram dietas com 1 ou $2 \%$ de óleo de peixe e girassol e observaram redução do colesterol da gema. Da mesma 
forma, Murata et al. (2003), alimentando poedeiras com 3\% de óleo de soja, canola e peixe, descreveram diferenças significativas no conteúdo de colesterol total da gema. Entretanto, as rações com óleo de peixe eóleo de soja resultaram em valores mais altos e mais baixos, respectivamente.

Controversamente, Mendonça Jr. et al. (2000) não obtiveram reduções significativas no colesterol da gema quando utilizaram óleo de peixe como fonte lipídica na ração de poedeiras com 89 semanas de idade. De forma similar, Caston \& Lesson (1990) utilizaram óleo de linhaça nos níveis de 10, 20 e 30\% e não observaram efeitos sobre o conteúdo de colesterol na gema. Hirata et al. (1986) também observaram que, embora o perfil de ácidos graxos da gema seja marcadamente influenciado pelo fornecimento de rações contendo diferentes fontes lipídicas (óleo de soja, óleo de coco, banha ou sebo), o teor de colesterol não sofre alteração significativa.

Normalmente as poedeiras recebem rações com baixo nível ou sem colesterol, dessa forma, a maior quantidade do colesterol do ovo e dos tecidos é de origem endógena. Quando grande quantidade de colesterol é adicionada à ração, a biossíntese hepática desse esterol é reduzida e, com isso, aumenta a quantidade de colesterol excretado nas fezes. Todavia, a síntese de colesterol ovariano permanece inalterada (Naber, 1983). Isso ocorre porque, embora o colesterol presente na gema do ovo seja sintetizado no fígado e transportado via corrente sanguínea na forma de lipoproteínas, a concentração do colesterol plasmático não está estritamente associada à concentração de colesterol da gema (Sutton et al., 1984).

Além disso, estudos in vitro comprovam que as membranas ao redor do ovário sintetizam colesterol a partir do acetato e não dependem do colesterol dietético (Weiss \& Scott, 1979). A taxa de deposição de colesterol no ovo reduz com o aumento na produção de ovos e é inversamente proporcional ao tamanho do ovo (Bitman \& Wood, 1980).

Considerando as controvérsias entre os trabalhos citados e os resultados obtidos, neste estudo, parece não haver relação entre o tipo de óleo e o colesterol da gema, pois, se o óleo de linhaça é extremamente rico em ácido linolênico e se tivesse efeito sobre o colesterol da gema, os resultados obtidos por Prakash et al.(1996) e Murata et al.(2003) seriam confirmados.

\section{Conclusões}

A inclusão de óleo de linhaça ou de soja, com ou sem vitamina E, e a adição de carvão vegetal na ração de poedeiras, não alteram o desempenho das aves nem reduzem as concentrações lipídicas do sangue e de colesterol total do ovo. As aves Lohmann LSL apresentaram maiores consumos de ração e níveis mais altos de colesterol e triglicérides no sangue.

\section{Referências}

AYMOND, W.M.; VAN ELSWYK, M.E. Yolk thiobarbituric acid reactive substances and $\mathrm{n}-3$ fatty acids in response to whole and ground flaxseed. Poultry Science, v.74, n.8, p.1388-1394, 1995.

BITMAN, J.; WOOD, D.L. Cholesterol and cholesteryl esters of eggs from avian species. Poultry Science, v.59, p.2014-2023, 1980.

BRAGA, C.V.P.; FUENTES, M.F.F.; FREITAS, E.R. et al. Efeito da inclusão do farelo de coco em rações para poedeiras comerciais. Revista Brasileira de Zootecnia, v.34, n.1, p.76-80, 2005.

CASTON, L.; LEESON, S. Research note: dietary flax and egg composition. Poultry Science, v.69, n.9, p.1617-1620, 1990.

CASTON, L.; SQUIRES, E.S.; LESSON, S. Hen performance, egg quality, and sensory evaluation of eggs from SCWL hens fed dietary flax. Canadian Journal of Animal Science, v.74, p.347-353, 1994.

COSTA, F.G.P.; SOUZA, J.G.; SILVA, J.H.V. et al. Influência do óleo de linhaça sobre o desempenho e a qualidade dos ovos de poedeiras semipesadas. Revista Brasileira de Zootecnia, v.37, n.5, p.861-868, 2008.

EDWARDS, H.M.; JONES, V. Effect of dietary cholesterol on serum and egg cholesterol levels over a period of time. Poultry Science, v.43, n.4, p.877-879, 1964.

GARCIA, C.; ALBALA, C. Composicion lipídica de huevos de gallinas alimentadas con productos grasos y proteicos marinos. Archivos Latinoamericanos de Nutricion, v.48, n.1, p.71-76, 1998.

GOMÉZ, M.E.D.B. Modulação da composição de ácidos graxos poliinsaturados ômega 3 de ovos e tecidos de galinhas poedeiras, através da dieta. I. Estabilidade oxidativa. 2003. 128f. Tese (Doutorado em Ciências Farmacêuticas) Universidade de São Paulo, São Paulo.

HARGIS, P.S.; VAM ELSWYK, M.E.; HARGIS, B.M. Dietary modification of yolk lipid with menhaden oil. Poultry Science, v.70, n.4, p.874-883, 1991.

HIRATA, A.; NISHINO, M.; KIMURA, T. et al. Effects of dietary fats for laying hens in the fatty acid compositions and cholesterol contents of liver, abdominal adipose tissue, plasma and egg yolk lipids. Journal of the Japanese Society of Food Science Technology, v.33, p.631-639, 1986.

HOLLAND, K.G.; GRUNDER, A.A.; WILLIAMS, C.J. Response to five generations of selection for blood cholesterol levels in White Leghorns. Poultry Science, v.59, n.6, p.1316-1323, 1980 .

JIANG, Z.R.; AHN, D.U.; SIM, J.S. Effect of feeding flaxseed and two types of sunflower seed on fatty acid compositions of yolk lipid classes. Poultry Science, v.70, n.12, p.2467-2475, 1991a.

JIANG, Z.R.; FENTON, M.; SIM, J.S. Comparison of four different methods for egg cholesterol determination. Poultry Science, v.70, n.4, p.1015-1019. 1991b.

JIANG, Z.R.; AHN, D.U.; LADNER, L. et al. Influence of feeding full-fat flax and sunflower seeds on internal and sensory qualities of eggs. Poultry Science, v.71, n.2, p.378-382, 1992.

JUDICE, M.P.M.; BERTECHINI, A.G.; MUNIZ, J.A. et al. Balanço cátion-aniônico das rações e manejo alimentar para poedeiras de segundo ciclo. Ciência Agrotécnica, v.26, n.3, p.598-609, 2002.

KLASING, K.C. Comparative avian nutrition. Wallingford: CAB International, 1998. 350p. 
KUTLU, H.R.; UNSAL, I.; GORGULU, M. Effects of providing dietary wood (oak) charcoal to broiler chicks and laying hens. Animal Feed Science and Technology, v.90, p.213-226. 2001.

LiMA, A.O.; SOARES, J.B.; GRECO, J.B. et al. Métodos de laboratório aplicados à clínica: técnica e interpretação. 8.ed. Rio de Janeiro: Guanabara Koogan, 2001. 850p.

MAZALLI, M.R.; SALDANHA, T.; BRAGAGNOLO, N. Determinação de colesterol em ovos: comparação entre um método enzimático e um método por cromatografia líquida de alta eficiência. Revista do Instituto Adolfo Lutz, v.62, n.1, p.49-54, 2003.

MAZALLI, M.R.; FARIA, D.E.; SALVADOR, D. et al. A comparison of the feeding value of different sources of fats for laying hens: 1 . performance characteristics. Journal of Applied Poultry Research, v.13, n.2, p.274-279, 2004.

MENDONÇA JR., C.X.; MARTINS, A.P.; MORI, A.A.V. et al. Efeito da adição de óleo de canola e de soja à ração sobre os níveis de lípides plasmáticos e desempenho de galinhas poedeiras. In: SIMPÓSIO DE INICIAÇÃO CIENTÍFICA DA USP, 3., 1995, Piracicaba. Anais... Piracicaba, 1995. p.354.

MENDONÇA JR, C.X.; MARTINS, A.P.; MORI, A.V. et al. Efeito da adição de óleo de peixe à dieta sobre o desempenho e níveis de lipídios plasmáticos e de colesterol no ovo de galinhas poedeiras. Brazilian Journal of Veterinary Research and Animal Science, v.37, n.1, 2000. Disponível em: <http://www.scielo.br/scielo.php> Acesso em: 3/5/2009.

MORI, A.V.; MENDONÇA JR., C.X.; SANTOS, C.O.F. Effect of dietary lipid - lowering drugs upon plasma lipids and egg yolk cholesterol levels of laying hens. Journal of Agricultural and Food Chemistry, v.47, n.11, p.4731-4735, 1999.

MURATA, L.S.; ARIKI, J.; MACHADO, C.R. et al. Effect of oils sources on blood lipid parameters of commercial laying hens. Brazilian Journal of Poultry Science, v.5, n.3, p.203-206, 2003.

NABER, E.C. Nutrient and drug effects on cholesterol metabolism in laying hen. Federation Proceedings, v.42, p.2486-2493, 1983.

NOBLE, R.C.; COCCHI, M.; TURCHETTO, E. Egg fat: a case for concern? World's Poultry Science Journal, v.46, p.109-118, 1990.

OBA, A.; SOUZA, P.A.; SOUZA, H.B.A. et al. Características produtivas e níveis de colesterol total no sangue e nos ovos de poedeiras comerciais alimentadas com dietas suplementadas com cinza vegetal, cobre, crômio e probiótico. Revista Portuguesa de Ciências Veterinárias, v.100, n.555-556, p.205-210, 2005.

PRAKASH, H.; GOWDH, C.V.; DEVEGOWDA, G. Possible dietary modifications for reducing the egg cholesterol by using different oils in white Leghorn layers. Indian Journal of Poultry Science, v.31, n.3, p.168-172, 1996.
ROSTAGNO, H.S.; ALBINO, L.F.T.; DONZELE, J.L. et al. Tabelas brasileiras para aves e suínos: composição de alimentos e exigências nutricionais. Viçosa, MG: Universidade Federal de Viçosa, Departamento de Zootecnia, 2000. 141p.

SANTOS, C.O.F. Efeito da adição de óleos poliinsaturados à ração nos níveis de lípides plasmáticos e de colesterol no ovo de galinhas poedeiras. 1999. 87f. Dissertação (Mestrado em Clínica Veterinária) - Faculdade de Medicina Veterinária e Zootecnia, Universidade de São Paulo, São Paulo.

SCHEIDELER, S.E.; FRONING, G.W. The combined influence of dietary flaxseed variety, level, form, and storage conditions on egg production and composition among vitamin Esupplemented hens. Poultry Science, v.75, n.10, p.1221-1226, 1996.

SILVA, J.H.V. Exigências nutricionais de lisina para frangas de postura, leves e semipesadas, nas fases inicial, cria e recria. 2000. 149f. Tese (Doutorado em Zootecnia) Universidade Federal de Viçosa, Viçosa, MG.

SIM, J.S.; BRAGG, D.B. Effect of dietary factors on serum and egg yolk cholesterol levels of laying hens. Poultry Science, v.56, n.5, p.1616-1621, 1977.

SOUZA, P.A.; SOUZA, H.B.A.; OBA, A. et al. Níveis de colesterol no sangue, na carne e no ovo de poedeiras comerciais submetidas a dietas contendo cinza vegetal. In: CONFERÊNCIA APINCO’98 DE CIÊNCIA E TECNOLOGIA AVÍCOLAS, 1998, Campinas. Anais... Campinas, 1998. p.96.

SUTTON, C.D.; MUIR, W.M.; MITCHELL, G.E. Cholesterol metabolism in the laying hen as influencied by dietary cholesterol, caloric intake and genotype. Poultry Science, v.63, n.5, p.972-980, 1984.

TORTUERO, F.; BRENES, A.; RIOPÉREZ, J. The influence of intestinal (сеса) flora on serum and egg yolk cholesterol levels in laying hens. Poultry Science, v.54, n.6, p.1935-1938, 1975.

TULLET, S. Egg fat - is that bad? Food Science Technology Today, v.1, p.77-79, 1987.

TURATTI, J.M. A importância dos ovos numa dieta saudável. Óleos e Grãos, v.9, n.59, p.22-24, 2001.

UNIVERSIDADE FEDERAL DE VIÇOSA - UFV. Sistemas para análises estatísticas - SAEG. Versão 8.1. Viçosa, MG: Fundação Arthur Bernardes, 2003. 142p.

VAN ELSWYK, M.E.; HARGIS, B.M.; WILLIAMS, J.D. et al. Dietary menhaden oil contributes to hepatic lipidosis in laying hens. Poultry Science, v.73, n.5, p.653-662, 1994.

WANASUNDARA, U. N., SHAHIDI, F. Antioxidant and pro-oxidant activity of green tea extracts in marine oils. Food Chemistry, v.63, n.3, p.335-342, 1998.

WEISS, F.G.; SCOTT, M.L. Effects of dietary fiber, fat and total energy upon plasma cholesterol and other parameters in chickens. Journal of Nutrition, v.109, p.693-701, 1979. 